\title{
Birth outcome in women with breast cancer, cutaneous malignant melanoma, or Hodgkin's disease: a review
}

This article was published in the following Dove Press journal:

Clinical Epidemiology

23 December 2010

Number of times this article has been viewed

\section{Vivian Langagergaard}

Department of Clinical Epidemiology, Aarhus University Hospital, Aarhus, Denmark
Correspondence: Vivian Langagergaard Department of Clinical Epidemiology, Aarhus University Hospital,

Olof Palmes Alle 43-45, DK-8200

Aarhus N., Denmark

Tel +4589424800

Fax +4589424801

Email vl@dce.au.dk
Background: Data on birth outcome in women diagnosed with cancer before, during, or shortly after pregnancy are very sparse. The purpose of this review was to summarize the existing epidemiologic evidence of the adverse effect of breast cancer, cutaneous malignant melanoma, and Hodgkin's disease on birth outcome.

Methods: The MEDLINE database was used to review the literature systematically. Studies that examined the following outcomes were included: preterm birth, low birth weight, low birth weight at term, stillbirths, congenital abnormalities, male proportion of newborns, and mean birth weight. Studies were grouped according to whether the woman had been diagnosed with the specific cancer before, during, or shortly after pregnancy.

Results: Few data exist on birth outcome in women with breast cancer, melanoma, or Hodgkin's disease. The overall results from the limited number of studies, which included a comparison group for birth outcome, were reassuring. However, for women diagnosed with breast cancer before pregnancy, the only 2 studies that included comparison groups for birth outcome had conflicting results regarding the risk of preterm birth and congenital abnormalities. Furthermore, a recent cohort study of birth outcome in women who were diagnosed with Hodgkin's disease before pregnancy indicated a slightly increased risk of congenital abnormalities among the newborns.

Conclusion: Overall, the existing studies offer reassuring results concerning the risks of adverse birth outcome for women diagnosed with breast cancer, melanoma, or Hodgkin's disease before, during or shortly after pregnancy. A limitation of most studies was the imprecise risk estimates caused by the small number of adverse birth outcomes and the lack of results stratified by treatment. Therefore, international collaboration is necessary in the future, to obtain more precise risk estimates for adverse birth outcomes, and to allow stratified analyses according to, for example, treatment.

Keywords: epidemiology, breast cancer, melanoma, Hodgkin's disease, birth outcome

\section{Introduction}

In Western countries women often postpone childbearing for personal or professional reasons. ${ }^{1}$ The average age of Danish women at their first delivery has gradually increased from 23 years in the 1960 s to 29 years in $2008 .^{2}$ Because the incidence rates of most cancers increase with advancing age ${ }^{3}$ more women can be expected to be diagnosed with cancer before childbearing, during pregnancy, or shortly after giving birth.

In Denmark, the most common malignancy affecting women of childbearing age is breast cancer, and the second most common one is cutaneous malignant melanoma (excluding nonmelanoma skin cancer). ${ }^{3}$ Hodgkin's disease, whose incidence peaks in early adulthood and thus also affects women of childbearing age, belongs to cancers 
with a good prognosis. ${ }^{4}$ While in previous decades pregnancy in patients with a history of cancer was discouraged, ${ }^{5}$ currently such pregnancies are treated with more optimism, partly owing to the improved prognosis for several cancers, ${ }^{6}$ and partly because pregnancies subsequent to breast cancer, for example, do not seem to adversely affect maternal life expectancy. $^{7-9}$ Because of a growing population of young cancer survivors, however, concerns have been raised about the adverse effects of cancer and cancer therapy on the offspring of the treated individuals. ${ }^{10}$ Offspring include those conceived after completion of treatment, and fetuses exposed to cancer therapy in utero. Data on birth outcome in women diagnosed with cancer before, during, or shortly after pregnancy are very sparse. Thus the purpose of this review was to summarize the existing epidemiologic evidence of the adverse effect of breast cancer, cutaneous malignant melanoma, and Hodgkin's disease on birth outcome.

\section{Incidence of breast cancer, cutaneous malignant melanoma, and Hodgkin's disease in women of childbearing age Breast cancer}

Breast cancer is the most common female cancer in Denmark with more than 4000 women diagnosed every year (approximately 400 women are younger than 45 years of age at the time of diagnosis). ${ }^{3}$ The age-standardized incidence rate of breast cancer has almost doubled over the last 4 decades, but this increase is mainly confined to women aged between 45 and 75 years. ${ }^{11}$ The incidence of breast cancer in pregnancy is unknown, but is estimated to range from 1 in 3000 to 1 in 10,000 pregnancies. $^{12}$

\section{Cutaneous malignant melanoma}

For decades, the incidence of cutaneous malignant melanoma has been rising in most white populations around the world. ${ }^{13}$ In Denmark, the incidence of melanoma for women aged 15 to 34 years increased, on average, by $4.3 \%$ annually from 1970 to $1999,{ }^{14}$ and in recent years, approximately 270 Danish women younger than 45 years have been diagnosed annually with melanoma. ${ }^{3}$ It has been estimated that melanoma represents approximately $8 \%$ of malignancies diagnosed during pregnancy. ${ }^{15}$

\section{Hodgkin's disease}

Hodgkin's disease is characterized by a bimodal age incidence curve, with the first peak in young adults and the second in old-age groups. ${ }^{16}$ While age standardized incidence of Hodgkin's disease has been declining slightly over time, the true incidence in older age groups has in fact decreased substantially, whilst among young adults in industrialized countries increases have been documented. ${ }^{16}$ In 2000 , 29 women younger than 45 years of age were diagnosed with Hodgkin's disease in Denmark. ${ }^{17}$ Hodgkin's disease during pregnancy has a reported incidence ranging from 1 per 100,000 to 1 per 6000 deliveries. ${ }^{18,19}$

\section{Definition of birth outcomes}

This review focuses on the prevalence of specific birth outcomes for children of cancer patients. It does not examine the risk of spontaneous or induced abortions, or diseases diagnosed later in life. The birth outcomes examined are defined below:

\section{Preterm birth}

Preterm birth is defined as delivery before 37 completed weeks of gestation. The time of delivery depends both on the natural course of the pregnancy and on clinical interventions, which may either shorten or prolong gestation. Given this mixture of spontaneous events and effects of medical interventions, the outcome of preterm birth itself is heterogeneous. ${ }^{20}$

\section{Low birth weight}

Low birth weight (LBW) is defined as birth weight of less than $2500 \mathrm{~g}$. Children in this group represent a mix of newborns whose growth is suboptimal, newborns delivered early, and newborns who are small for genetic reasons. ${ }^{20}$ As an alternative, some studies use "LBW at term" (defined as birth weight less than $2500 \mathrm{~g}$ in those born at least 37 weeks after conception), which suggests that the child remains small despite having had adequate time for growth. ${ }^{20}$ The presumption is that a child with LBW at term is likely to be growth retarded.

\section{Stillbirth}

In Denmark stillbirth is defined as antepartum or intrapartum fetal death after 22 completed weeks of pregnancy. Before 2004 only fetal deaths after 28 completed weeks of pregnancy were considered stillbirths.

\section{Congenital abnormalities}

Congenital abnormalities occur in $3 \%$ to $5 \%$ of all livebirths. ${ }^{20}$ However, each individual type of congenital abnormality is rare, with the most common occurring in about $1 / 1000$ live births. ${ }^{20}$ The etiologic events that generate structural abnormalities typically occur within the first 
2 to 8 weeks post-conception, but the recognition of the abnormality may not occur until later in pregnancy (during ultrasound evaluation), at birth, in early childhood, or in adulthood, or the abnormality may never be recognized.

\section{Male proportion of newborns}

Approximately $51 \%$ of live-born children in Denmark are boys.

\section{Methods}

The epidemiologic evidence of the possible adverse effect of maternal breast cancer, melanoma, and Hodgkin's disease on birth outcome was examined via a systematic literature review, including studies published before January 2010.

To review the literature, I searched the MEDLINE database and used the MeSH (Medical Subject Heading) terms "breast neoplasms", "melanoma", and "Hodgkin disease" [MAJR] (Major Topic headings only), respectively, in combination with "pregnancy" [MAJR], limiting the search to include only studies on human females, in English, and with an abstract. More studies were identified through communication with other researchers and by reviewing the reference lists of relevant articles. Studies were classified as case-series, if they reported birth outcome in a cohort of women with cancer without comparing it with the outcome of a comparison group. However, if the authors computed risk estimates for adverse birth outcome in comparison with the general population, the study was classified as a cohort study.

The studies listed in Tables 1, 2, and 3 were selected according to these criteria: studies of birth outcome in women who were diagnosed with breast cancer, melanoma, or Hodgkin's disease at any time before pregnenancy (including childhood), during pregnancy, or within 2 years after delivery were included. I selected only studies that examined preterm birth, LBW (or LBW at term), stillbirths, congenital abnormalities, male proportion of newborns, and/or mean birth weight. I excluded studies that reported overall risks of adverse birth outcome for survivors of different cancers combined. In addition, I excluded reviews, case-reports, case-series, and comments from the tables. However, given that the overall evidence on the topic is sparse, there are some references to case-series in the text.

\section{Results}

Below is a summary of the existing epidemiologic evidence of the adverse effect of maternal breast cancer, melanoma, and Hodgkin's disease on birth outcome. The studies of birth outcome in women with, respectively, breast cancer, melanoma, and Hodgkin's disease (Tables 1, 2, and 3) were selected according to the inclusion criteria described under Methods. No case-control study fulfilled the inclusion criteria.

\section{Birth outcome in women with breast cancer}

Data on birth outcome in women diagnosed with breast cancer before pregnancy are very sparse. Small case series have reported births of healthy children to women who became pregnant after being diagnosed with breast cancer. ${ }^{21,22}$ The only 2 studies with a comparison group for birth outcome that have been published, however, had conflicting results on the risk of preterm birth and congenital abnormalities after breast cancer (Table 1). ${ }^{23,24}$ In a registry-based cohort study from Sweden, Dalberg et al examined 331 births from 1973 to 2002, to women who were diagnosed with breast cancer before pregnancy. ${ }^{24}$ Dalberg et al found that a large majority of these births were free of adverse events, and reported no increased risk of stillbirth or reduced birth weight for gestational age. However, the study also reported an increased risk of very preterm birth ( $<32$ weeks) (odds ratio $[\mathrm{OR}]=3.2 ; 95 \%$ confidence interval $[95 \% \mathrm{CI}]: 1.7-6.0)$ and LBW $(<1500 \mathrm{~g})(\mathrm{OR}=2.9$; 95\% CI: 1.4-5.8) and an increased risk of congenital abnormalities $(\mathrm{OR}=1.7 ; 95 \%$ CI: 1.1-2.5) among children of breast cancer survivors, compared with the general population. The increased risk of congenital abnormalities was seen especially in the births occurring in 1988 to 2002 (OR $=2.1$; 95\% CI: 1.2-3.7), which the authors explained by an increased use of chemotherapy in younger patients. The study, however, had no data on the treatment of women with breast cancer. In contrast, a nationwide Danish cohort study of 216 newborns of women diagnosed with breast cancer before pregnancy found no increased risk with respect to preterm birth, LBW at term, stillbirth, and congenital abnormalities as well as mean birth weight, compared with the outcomes of 33,443 births from unaffected mothers, and with results unaltered by stratification by a treatment variable. ${ }^{23}$ As suggested by Dalberg et al the different results in the Swedish and the Danish cohorts may be caused by different degrees of misclassification of the outcome variables between the registries or differences in the use of adjuvant radiotherapy or systemic treatments after breast cancer.

The Danish cohort study also observed an 8-fold increased risk of preterm delivery among 37 women diagnosed with breast cancer during pregnancy, which reflected a higher rate of elective early delivery, probably to allow an early start to cancer therapy. After adjustment for gestational 


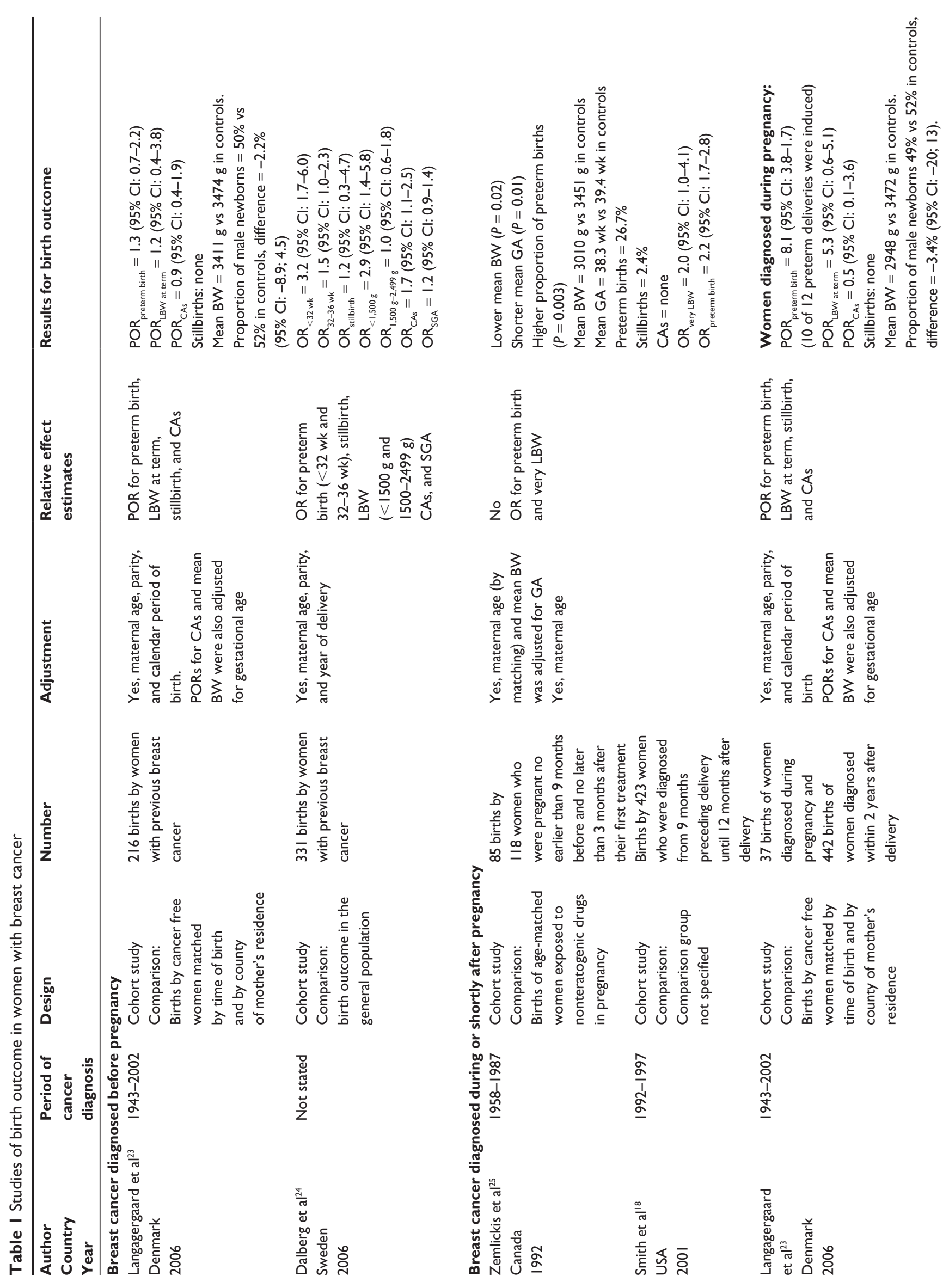




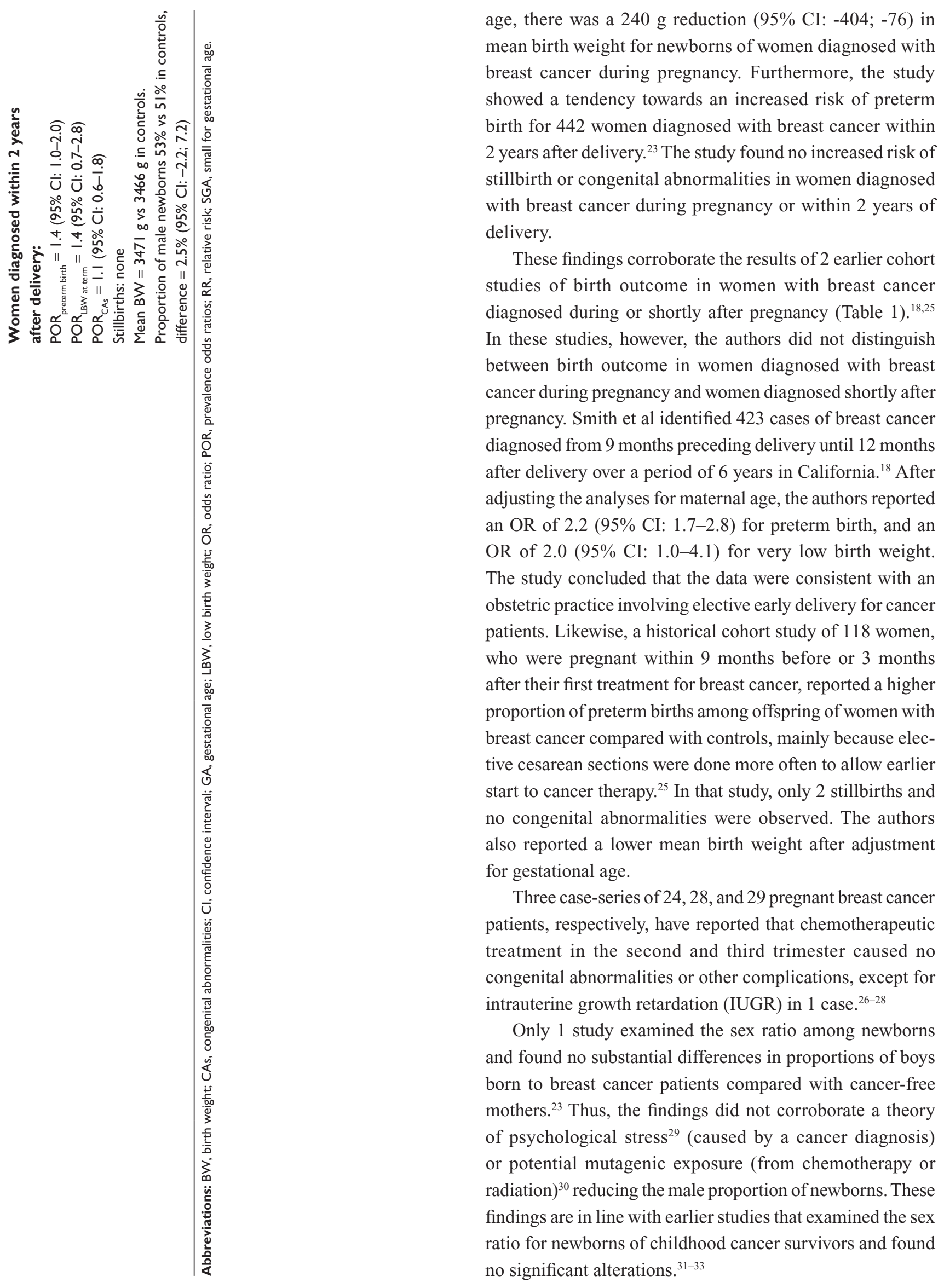




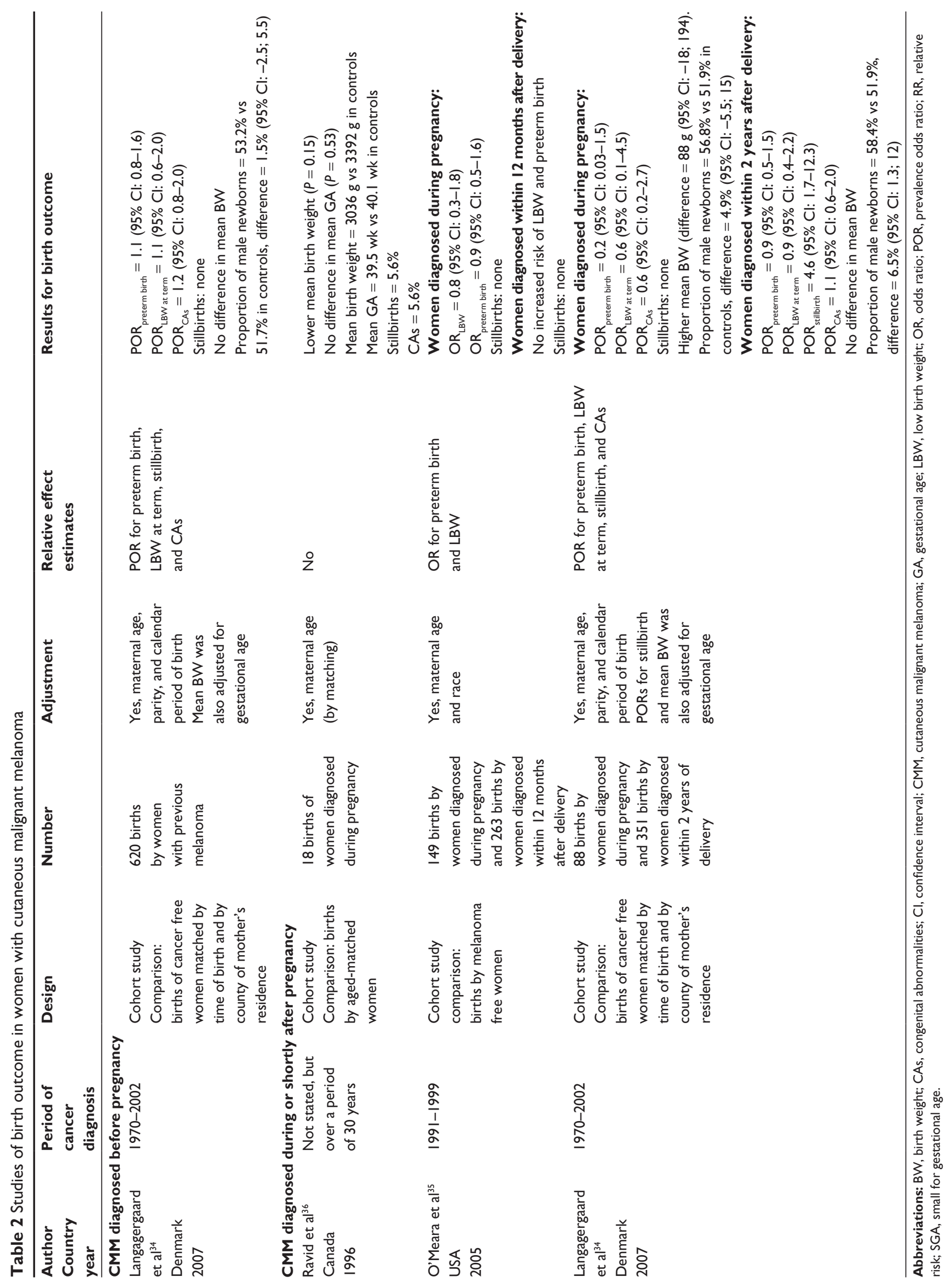




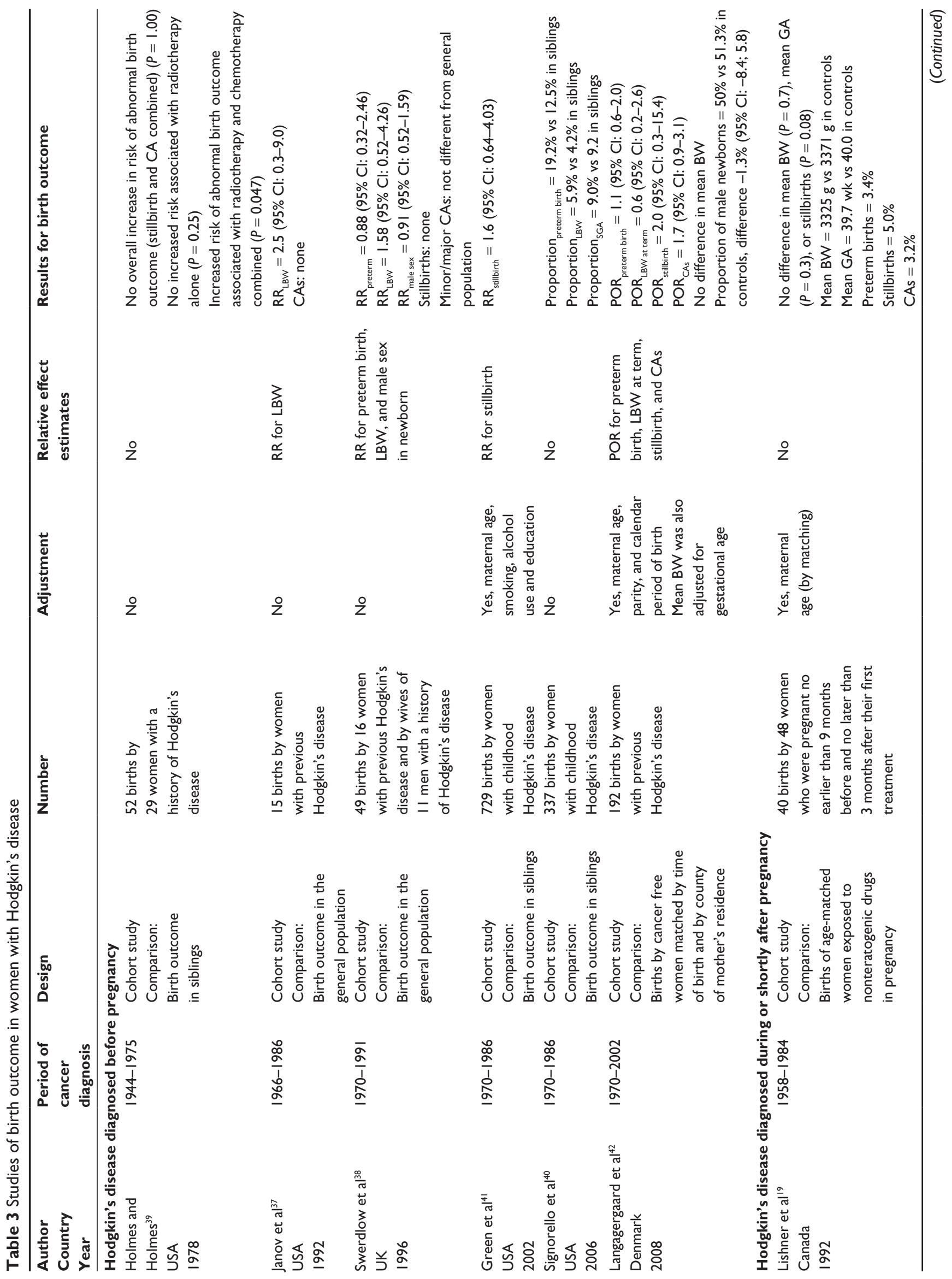




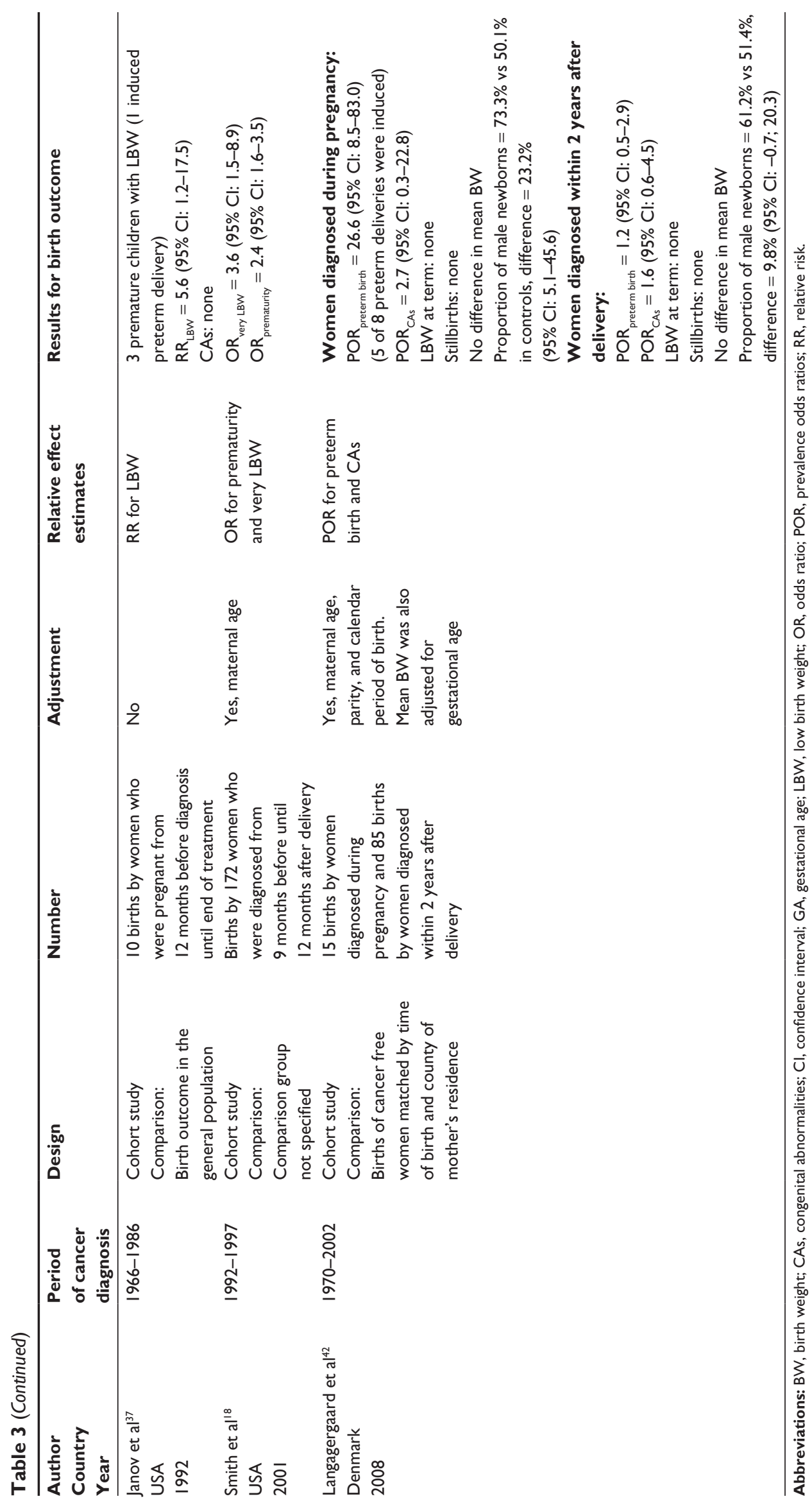


In conclusion, the overall results regarding the birth outcome among women with breast cancer are reassuring. However, additional studies of birth outcome in women who were diagnosed with breast cancer before pregnancy are needed to resolve the discrepancy between the findings of the Danish ${ }^{23}$ and the Swedish ${ }^{24}$ study.

\section{Birth outcome in women with cutaneous malignant melanoma}

A nationwide cohort study from Denmark (Table 2) found no excess risk with respect to preterm birth, LBW at term, stillbirth, and congenital abnormalities among 620 newborns of women who were diagnosed with melanoma before pregnancy or 88 newborns of women who were diagnosed during pregnancy, compared with, respectively, 29,788 and 4180 newborns of cancer free women. ${ }^{34}$ Furthermore, there was no important difference in mean birth weight or male proportion of newborns between women with melanoma and comparison women. However, the study reported a prevalence odds ratio (POR) of 4.6 (95\% CI: 1.7-12.3) for stillbirth among 351 newborns of women, who were diagnosed with melanoma within 2 years after the time of delivery. This finding, which was unexpected, has not been shown by other studies, and may have been a chance finding.

Two other cohort studies have examined birth outcome in offspring of women diagnosed with melanoma during or shortly after pregnancy (Table 2). ${ }^{35,36}$ In a hospital-based cohort study of 18 deliveries by women diagnosed with melanoma during pregnancy over a period of 30 years, there were 17 live births and 1 anencephalic stillbirth. ${ }^{36}$ The newborns of women with melanoma had a lower mean birth weight than newborns of women without cancer, but there was no difference in mean gestational age. The authors suggested that the differences in birth weight were due to IUGR secondary to the melanoma, its therapies, or its complications. In that study, however, mean birth weights were based on only 9 melanoma-exposed newborns and 9 newborns of age-matched comparison mothers.

In a population-based cohort study, O'Meara et al identified 149 women diagnosed with melanoma during pregnancy and 263 women diagnosed within 12 months after delivery over a period of 9 years in California. ${ }^{35}$ That study and the Danish study ${ }^{34}$ were in agreement with respect to the findings of no increased risk of preterm birth or low birth weight among newborns of mothers with melanoma. For women diagnosed during pregnancy, O'Meara and colleagues reported an OR of 0.9 (95\% CI: 0.5-1.6) for preterm birth and an OR of 0.8 (95\% CI: 0.3-1.8) for LBW, adjusted for age and race. They found no fetal deaths in the exposed group and no increased risk of adverse birth outcome in women diagnosed with melanoma in the first post partum year. The study did not examine the risk of congenital abnormalities among newborns.

The overall results from these studies show no substantially increased risk of adverse birth outcome for women with melanoma, with the possible exception of an increased risk of stillbirth for newborns of women diagnosed within 2 years of delivery.

\section{Birth outcome in women with Hodgkin's disease}

More studies have examined birth outcome in women with previous Hodgkin's disease. Janov et al did not find any substantial increased risk of LBW and no congenital abnormalities among newborns of 15 women with prepregnancy Hodgkin's disease compared with the general population (Table 3). ${ }^{37}$ Likewise, Swerdlow et al reported no increased risk of preterm birth, LBW, stillbirth, or congenital abnormalities among 49 children of 16 women and 11 men who had previously been treated for Hodgkin's disease compared with the general population (Table 3). ${ }^{38}$ Another study, which compared 52 births by 29 women previously treated for Hodgkin's disease with births by the women's siblings, found no overall increased risk of congenital abnormalities and stillbirths combined among children of Hodgkin's disease patients. The study also found no association of birth outcome with radiotherapy alone (supra- or infradiaphragmatic), whereas women treated with both chemotherapy and radiation were more likely to give birth to an abnormal child $(P=0.047)$ (Table 3$)$. The 3 studies, however, were all based on small study populations and did not control for potential confounders.

Recently, a large cohort study of female survivors of childhood cancer found that $19.2 \%$ of 337 women with childhood Hodgkin's disease had a preterm birth compared with $12.6 \%$ among sibling controls (Table 3 ). ${ }^{40}$ Another study reported 11 stillbirths among 729 births of female survivors of childhood Hodgkin's disease, corresponding to a relative risk of 1.6 (95\% CI: 0.64-4.03) (Table 3). ${ }^{41}$ In contrast, a recent Danish cohort study of birth outcome in women with previous Hodgkin's disease found no increased risk of preterm birth and only 1 stillbirth among 192 women, of whom more than $75 \%$ had been diagnosed with Hodgkin's disease in adulthood ( $\geq 20$ years of age at diagnosis) (Table 3) ${ }^{42}$ The results from the Danish study, however, indicated a slightly increased risk of congenital abnormalities among newborns of women with previous Hodgkin's 
disease $(\mathrm{POR}=1.7 ; 95 \% \mathrm{CI}: 0.9-3.1)$. Furthermore, it was reported, that the POR for congenital abnormalities increased with calendar time of Hodgkin's disease diagnosis (ie, for 1991-2000 the POR was 3.1 (95\% CI: 1.4-6.9) compared with POR $=1.0$ (reference) for 1970-1980)..$^{42}$

The Danish study also reported increased risk estimates for congenital abnormalities among newborns of women who were diagnosed with Hodgkin's disease during or shortly after pregnancy, but these estimates were based on few outcomes and were therefore imprecise. However, it is important to emphasize that teratogens increase the rate of specific, rather than all abnormalities, and the study was unable to evaluate those.

Two studies reported an increased risk of preterm birth for women diagnosed with Hodgkin's disease during pregnancy, which reflected a higher rate of elective early delivery (Table 3). ${ }^{18,42}$ In contrast, a historical cohort study by Lishner et al which included 40 births by women who were pregnant between 9 months before and 3 months after their first treatment for Hodgkin's disease, reported no increased risk of preterm birth or induced deliveries (Table 3). ${ }^{19}$ Furthermore, the study indicated no difference in mean birth weight compared with controls, while the proportion of stillbirths was not statistically different from that of the general population. The study reported 1 child with a congenital abnormality born to the only patient treated with chemotherapy in the first trimester.

There was no evidence of any substantial decrease in the male proportion of newborns among women diagnosed with Hodgkin's disease before pregnancy, indicating that earlier treatment for Hodgkin's disease is not a risk factor for early male abortion. ${ }^{42}$

For newborns of women diagnosed with Hodgkin's disease during pregnancy, there was an increase in the male proportion, compared with newborns of comparison mothers, which was surprising and could have been a chance finding. ${ }^{42}$

In conclusion, the overall results are reassuring regarding the risks of adverse birth outcome for women with Hodgkin's disease, although the possibility of an increased risk of congenital abnormalities in newborns of women diagnosed with Hodgkin's disease before pregnancy cannot be ruled out.

\section{Discussion}

\section{Possible adverse effects of cancer} and cancer therapy on birth outcome

When cancer is diagnosed in pregnancy, there is often a conflict between optimal maternal therapy and fetal well-being. ${ }^{5}$ The benefit of the diagnostic work-up, surgery, radiotherapy and chemotherapy must be weighed carefully against the risk to the fetus. ${ }^{12}$ Under these circumstances, preterm labor is often induced as soon as the fetus becomes viable, in order to allow amplification of therapy. ${ }^{12}$

The rationale for examining birth outcome in women diagnosed with cancer within a few years after delivery is that pregnancies starting before the diagnosis may be affected by the preclinical cancer. A Swedish study, which compared observed to expected rates of cancer during pregnancy and during the first year after delivery, suggested that diagnosis is often delayed to the postpartum period. ${ }^{43}$ A possible explanation for this delay could be that unusual signs and symptoms may be ascribed to the pregnancy rather than the cancer.

For women who retain or regain fertility after cancer treatment, an issue of great importance is their ability to carry a pregnancy to term and give birth to a normal child. Chemotherapy and radiotherapy may affect future pregnancies in cancer survivors by directly affecting the reproductive tract or by causing mutations in germ cells. ${ }^{30}$ It is therefore important to establish the magnitude of an increased risk (if any) of adverse birth outcomes such as preterm birth, LBW (or LBW at term), stillbirth, and congenital abnormalities.

\section{Possible adverse effects of the cancer itself on birth outcome}

Little is known about exact mechanisms whereby maternal cancer may pose risk to a developing fetus. In theory, several factors might influence the fetus if the mother has malignant disease:

- It has been proposed that the cancer may alter metabolism and distribution of hormones and vitamins, some of which are determinants for certain congenital abnormalities. ${ }^{44}$

- Cancer patients have an increased tendency to suffer from febrile illness, ${ }^{5}$ and maternal fever in early pregnancy has been associated with stillbirth ${ }^{45}$ and congenital abnormalities. ${ }^{45,46}$

- Malnutrition is more frequent in the patients. Maternal undernutrition during pregnancy resulting in reduced transfer of nutrients to the fetus may cause fetal undernutrition and intrauterine growth retardation. ${ }^{47}$ Impaired fetal growth is strongly associated with neonatal morbidity and mortality, ${ }^{48}$ and may also be associated with diseases later in life. ${ }^{49}$

- Psychological stress related to severe life events (eg, a cancer diagnosis) around the time of conception may reduce the male proportion of newborns through differential conception or differential abortion of male embryos. ${ }^{29}$ 
Likewise, some studies have reported associations of stress in pregnancy with preterm delivery, ${ }^{50,51}$ and congenital abnormalities. ${ }^{52}$

\section{Possible adverse effects of specific cancer therapy on birth outcome \\ Surgery}

Most surgical interventions can be safely undertaken with minimum risk during pregnancy, although there is almost always some element of maternal-fetal conflict. ${ }^{53}$

\section{Radiation}

Radiation is commonly used for cancer diagnosis and treatment. The fetus is sensitive to ionizing radiation, with the brain being the most sensitive organ. ${ }^{54}$ During the periimplantation and immediate post-implantation periods, radiation has an all or nothing effect, resulting in either embryonic death or further normal development. Later in pregnancy, radiation may cause congenital abnormalities, IUGR, mental retardation, or childhood cancer. ${ }^{54}$ As a result, the general recommendation is to postpone radiotherapy until after delivery. ${ }^{12}$ At the same time, births of healthy children after radiotherapy of pregnant women for breast cancer and supradiaphragmatic Hodgkin's disease have been reported (with appropriate shielding of the fetus). ${ }^{19,55-57}$

In nonpregnant women of childbearing age, ionizing radiation may damage ovarian function, cause premature ovarian failure, or trigger germ cell mutations, which can lead to congenital abnormalities in future offspring. ${ }^{30}$

Studies of women exposed to the atomic-bomb radiation and their subsequently conceived offspring have indicated a higher rate of spontaneous abortion, but showed no increase in the risk of major congenital abnormalities compared with the children of women from the general population. ${ }^{10}$ These results corroborate studies of childhood cancer survivors reporting no increased risk of congenital abnormalities or genetic diseases in the offspring of women exposed to pre-gestational radiotherapy. ${ }^{58-61}$

It has also been postulated that maternal gonadal exposure to radiation would decrease the male proportion of newborns by inducing recessive sex-linked lethal mutations. ${ }^{62}$ In addition, women previously treated with high-dose abdominal radiotherapy have been found to have an increased risk of spontaneous abortions, ${ }^{41,63,64}$ preterm deliveries,${ }^{40}$ and LBW infants ${ }^{58,59,63}$ during subsequent pregnancies. These effects are most likely due to radiation-induced damage to the women's abdominopelvic structures. ${ }^{10,59}$
Traditional ways to protect the ovaries against the radiation damage are shielding of the ovaries and, in case of pelvic lymph node irradiation, repositioning of the ovaries out of the irradiation field (oopheropexy). ${ }^{65}$ Today, many young patients needing radiotherapy (or chemotherapy) are offered the option of cryopreservation of their ovarian tissue, while recent studies of ovarian tissue autotransplantation offer promising results. ${ }^{66}$

\section{Chemotherapy}

A potential teratogenic effect of chemotherapy during pregnancy depends on the agent used, the timing of exposure, the dose, and the characteristics affecting placental transfer.

Use of chemotherapy during the first trimester increases the risk of miscarriage and congenital abnormalities. ${ }^{26}$ A review of 139 cases of first-trimester exposure to chemotherapy reported a total of $24(17 \%)$ infants with congenital abnormalities after a single agent exposure, and a prevalence of $25 \%$ after combination-agent exposure. ${ }^{67}$

Chemotherapy during the second and third trimesters may increase the risk of preterm birth, IUGR, and stillbirth. ${ }^{12}$ Furthermore, the central nervous system continues to develop after the first trimester, which makes it sensitive to insults during the entire pregnancy. ${ }^{12}$ While exposure to chemotherapy after the first trimester does not cause macroscopic anatomical defects, it may have long-term subanatomical consequences, for example, by interfering with the neuronal proliferation and migration. ${ }^{12}$ However, a study of late side effects among 84 children whose mothers received chemotherapy, during pregnancy, for hematological malignancies did not show impairments in learning behavior, or neurological abnormalities after a median follow-up of 18 years. ${ }^{68}$ Given all the evidence, it is generally recommended that chemotherapy is delayed until after the first trimester. ${ }^{12}$

In nonpregnant women of childbearing age, chemotherapy can adversely affect fertility. ${ }^{69}$ Damage to the ovarian tissue depends on the agent used, the dose, and the age of the patient at treatment. ${ }^{70}$ Furthermore, chemotherapy is potentially mutagenic ${ }^{10}$ with animal studies showing that it can cause mutations in oocytes and increase the risk of fetal abnormalities. ${ }^{65}$

\section{Endocrine therapy}

The use of anti-estrogenic therapy, such as tamoxifen, in pregnant breast cancer patients has been discouraged because of teratogenic effects seen in animal models. ${ }^{12}$ Direct evidence for teratogenesis in humans is limited, with only isolated reports of rare forms of congenital abnormalities associated with tamoxifen use. ${ }^{71}$ 


\section{Conclusions and perspectives}

This review summarizes the existing epidemiologic evidence of the adverse effect of maternal breast cancer, melanoma, and Hodgkin's disease on birth outcome. On the whole, existing studies offer reassuring results concerning the risks of adverse birth outcome for women diagnosed with breast cancer, melanoma, or Hodgkin's disease before, during or shortly after pregnancy. However, a limitation of most studies was the imprecise risk estimates caused by the small number of adverse birth outcomes and the lack of results stratified by treatment. Since even countrywide data may be sparse, an international collaboration is required in order to assemble data on a sufficient number of births by women with cancer in order to obtain more precise risk estimates for adverse birth outcomes. Moreover, a larger number of birth outcomes would allow stratified analyses according to, for example, different treatment regimens, stages, and how close in time the cancer diagnosis was to pregnancy. Information on these clinical details could be obtained from hospital medical records and clinical databases.

Very few studies document the long-term follow-up of children exposed to maternal cancer and cancer treatment in utero. ${ }^{68}$ Maternal cancer may affect not only birth outcome, but also long-term health, as a consequence of intra-uterine programming. Thus, large cohort studies with long term follow-up are needed to evaluate the entire spectrum of adverse effects of cancer or cancer treatment on offspring of the patients.

\section{Disclosure}

The contents of this review have previously been included in a $\mathrm{PhD}$ thesis.

\section{References}

1. Dow KH, Harris JR, Roy C. Pregnancy after breast-conserving surgery and radiation therapy for breast cancer. J Natl Cancer Inst Monogr. 1994; (16):131-137.

2. Statistics Denmark. FOD11: Mean age of Danish women at first delivery. http://www.statistikbanken.dk/FOD11/. Accessed Mar 152010.

3. Nye tal fra Sundhedsstyrelsen 2009: Cancerregisteret 2008. http://www. sst.dk/publ/Publ2009/DOKU/cancerreg/cancerregisteret_2008.pdf. Accessed Mar 152010 .

4. Fisher PM, Hancock BW. Hodgkin's disease in the pregnant patient. Br J Hosp Med. 1996;56(10):529-532.

5. Koren G, Lishner M, Zemlickis D. Cancer in pregnancy: identification of unanswered questions on maternal and fetal risks. In: Koren G, Lishner M, Farine D, editors. Cancer in pregnancy: Maternal and fetal risks. Cambridge: Cambridge University Press; 1996:3-14.

6. Rørth M, Storm H. Kraftsygdomme. Onkologi. Ringborg U, Henriksson R, Friberg S, editors. 2004.

7. Kroman N, Jensen MB, Melbye M, Wohlfahrt J, Mouridsen HT. Should women be advised against pregnancy after breast-cancer treatment? Lancet. 1997;350(9074):319-322.
8. Blakely LJ, Buzdar AU, Lozada JA, et al. Effects of pregnancy after treatment for breast carcinoma on survival and risk of recurrence. Cancer. 2004;100(3):465-469.

9. Kroman N, Jensen MB, Wohlfart J, Ejlertsen B; Danish Breast Cancer Cooperative Group. Pregnancy after treatment of breast cancer a population-based study on behalf of Danish Breast Cancer Cooperative Group. Acta Oncol. 2008;47(4):545-549.

10. Arnon J, Meirow D, Lewis-Roness H, Ornoy A. Genetic and teratogenic effects of cancer treatments on gametes and embryos. Hum Reprod Update. 2001;7(4):394-403.

11. Kroman NT, Lidegaard O, Kvistgaard ME. Breast cancer - a lifestyle disease?. Ugeskr Laeger. 2005;167(49):4636-4641.

12. Weisz B, Meirow D, Schiff E, Lishner M. Impact and treatment of cancer during pregnancy. Expert Rev Anticancer Ther. 2004;4(5):889-902.

13. Bevona C, Sober AJ. Melanoma incidence trends. Dermatol Clin. 2002; 20(4):589-595, vii.

14. Van der Horst M, Winther JF, Olsen JH. Cancer incidence in the age range 0-34 years: historical and actual status in Denmark. Int J Cancer. 2006;118(11):2816-2826.

15. Lishner M. Cancer in pregnancy. Ann Oncol. 2003;14 Suppl 3: iii31-iii36.

16. Melbye M, Adami H-O. Hodgkin's lymphoma. In: Adami H-O, Hunter D, Trichopoulos D, editors. Textbook of Cancer Epidemiology. New York: Oxford University Press; 2002:520-534.

17. Cancer incidens i Danmark 2000. Sundhedsstyrelsen. 2004. http://www. sst.dk/publ/tidsskrifter/nyetal/pdf/2004/17_04.pdf. Accessed Mar 15 2010 .

18. Smith LH, Dalrymple JL, Leiserowitz GS, Danielsen B, Gilbert WM. Obstetrical deliveries associated with maternal malignancy in California, 1992 through 1997. Am J Obstet Gynecol. 2001;184(7):1504-1512.

19. Lishner M, Zemlickis D, Degendorfer P, Panzarella T, Sutcliffe SB, Koren G. Maternal and foetal outcome following Hodgkin's disease in pregnancy. Br J Cancer. 1992;65(1):114-117.

20. Savitz DA, Hertz-Picciotto I, Poole C, Olshan AF. Epidemiologic measures of the course and outcome of pregnancy. Epidemiol Rev. 2002;24(2):91-101.

21. Sutton R, Buzdar AU, Hortobagyi GN. Pregnancy and offspring after adjuvant chemotherapy in breast cancer patients. Cancer. 1990;65(4): 847-850.

22. Malamos NA, Stathopoulos GP, Keramopoulos A, Papadiamantis J, Vassilaros S. Pregnancy and offspring after the appearance of breast cancer. Oncology. 1996;53(6):471-475.

23. Langagergaard V, Gislum M, Skriver MV, et al. Birth outcome in women with breast cancer. Br J Cancer. 2006:94(1):142-146.

24. Dalberg K, Eriksson J, Holmberg L. Birth outcome in women with previously treated breast cancer - a population-based cohort study from Sweden. PLoS Med. 2006;3(9):e336.

25. Zemlickis D, Lishner M, Degendorfer P, et al. Maternal and fetal outcome after breast cancer in pregnancy. Am J Obstet Gynecol. 1992; 166(3):781-787.

26. Cardonick E, Iacobucci A. Use of chemotherapy during human pregnancy. Lancet Oncol. 2004;5(5):283-291.

27. Berry DL, Theriault RL, Holmes FA, et al. Management of breast cancer during pregnancy using a standardized protocol. J Clin Oncol. $1999 ; 17(3): 855-861$

28. Ring AE, Smith IE, Jones A, Shannon C, Galani E, Ellis PA. Chemotherapy for breast cancer during pregnancy: an 18-year experience from five London teaching hospitals. J Clin Oncol. 2005; 23(18):4192-4197.

29. Hansen D, Moller H, Olsen J. Severe periconceptional life events and the sex ratio in offspring: follow up study based on five national registers. BMJ. 1999;319(7209):548-549.

30. Nagarajan R, Robison LL. Pregnancy outcomes in survivors of childhood cancer. J Natl Cancer Inst Monogr. 2005;(34):72-76.

31. Byrne J, Rasmussen SA, Steinhorn SC, et al. Genetic disease in offspring of long-term survivors of childhood and adolescent cancer. Am J Hum Genet. 1998;62(1):45-52. 
32. Hawkins MM. Is there evidence of a therapy-related increase in germ cell mutation among childhood cancer survivors? J Natl Cancer Inst. 1991;83(22):1643-1650.

33. Winther JF, Boice JD Jr, Thomsen BL, Schull WJ, Stovall M, Olsen JH. Sex ratio among offspring of childhood cancer survivors treated with radiotherapy. Br J Cancer. 2003;88(3):382-387.

34. Langagergaard V, Puho EH, Lash TL, Nørgård B, Sørensen HT. Birth outcome in Danish women with cutaneous malignant melanoma. Melanoma Res. 2007;17(1):31-36.

35. O’Meara AT, Cress R, Xing G, Danielsen B, Smith LH. Malignant melanoma in pregnancy. A population-based evaluation. Cancer. 2005; 103(6):1217-1226.

36. Ravid M, Lishner M, Zemlickis D, Koren G. Malignant melanoma and pregnancy. In: Koren G, Lishner M, Farine D, editors. Cancer in Pregnancy: Maternal and Fetal Risks. Cambridge: Cambridge University Press; 1996:134-142.

37. Janov AJ, Anderson J, Cella DF, Zuckerman E, Kornblith AB, Holland JC, et al. Pregnancy outcome in survivors of advanced Hodgkin disease. Cancer. 1992;70(3):688-692.

38. Swerdlow AJ, Jacobs PA, Marks A, et al. Fertility, reproductive outcomes, and health of offspring, of patients treated for Hodgkin's disease: an investigation including chromosome examinations. Br J Cancer. 1996;74(2):291-296.

39. Holmes GE, Holmes FF. Pregnancy outcome of patients treated for Hodgkin's disease: a controlled study. Cancer. 1978;41(4):1317-1322.

40. Signorello LB, Cohen SS, Bosetti C, et al. Female survivors of childhood cancer: preterm birth and low birth weight among their children. J Natl Cancer Inst. 2006;98(20):1453-1461.

41. Green DM, Whitton JA, Stovall M, et al. Pregnancy outcome of female survivors of childhood cancer: a report from the Childhood Cancer Survivor Study. Am J Obstet Gynecol. 2002;187(4):1070-1080.

42. Langagergaard V, Horvath-Puho $\mathrm{E}$, Nørgaard $\mathrm{M}$, Nørgård $\mathrm{B}$, Sørensen HT. Hodgkin's disease and birth outcome: a Danish nationwide cohort study. Br J Cancer. 2008;98:183-188.

43. Lambe M, Ekbom A. Cancers coinciding with childbearing: delayed diagnosis during pregnancy? BMJ. 1995;311(7020):1607-1608.

44. Zhu JL, Basso O, Hasle H, Winther JF, Olsen JH, Olsen J. Do parents of children with congenital malformations have a higher cancer risk? A nationwide study in Denmark. Br J Cancer. 2002;87(5):524-528.

45. Chambers CD, Johnson KA, Dick LM, Felix RJ, Jones KL. Maternal fever and birth outcome: a prospective study. Teratology. 1998; 58(6):251-257.

46. Tikkanen J, Heinonen OP. Maternal hyperthermia during pregnancy and cardiovascular malformations in the offspring. Eur J Epidemiol. 1991;7(6):628-635.

47. Wu G, Bazer FW, Cudd TA, Meininger CJ, Spencer TE. Maternal nutrition and fetal development. J Nutr. 2004;134(9):2169-2172.

48. McIntire DD, Bloom SL, Casey BM, Leveno KJ. Birth weight in relation to morbidity and mortality among newborn infants. $N$ Engl J Med. 1999;340(16):1234-1238.

49. Barker DJP. Fetal origins of coronary heart disease. BMJ. 1995; 311(6998):171-174.

50. Hedegaard M, Henriksen TB, Sabroe S, Secher NJ. Psychological distress in pregnancy and preterm delivery. BMJ. 1993;307(6898):234-239.

51. Hedegaard M, Henriksen TB, Secher NJ, Hatch MC, Sabroe S. Do stressful life events affect duration of gestation and risk of preterm delivery? Epidemiology. 1996;7(4):339-345.

\section{Clinical Epidemiology}

\section{Publish your work in this journal}

Clinical Epidemiology is an international, peer-reviewed, open access journal focusing on disease and drug epidemiology, identification of risk factors and screening procedures to develop optimal preventative initiatives and programs. Specific topics include: diagnosis, prognosis, treatment, screening, prevention, risk factor modification, systematic
52. Hansen D, Lou HC, Olsen J. Serious life events and congenital malformations: a national study with complete follow-up. Lancet. 2000; 356(9233):875-880.

53. Moran BJ, Yano H, Al Zahir N, et al. Conflicting priorities in surgical intervention for cancer in pregnancy. Lancet Oncol. 2007;8(6): 536-544.

54. Weisz B, Schiff E, Lishner M. Cancer in pregnancy: maternal and fetal implications. Hum Reprod Update. 2001;7(4):384-393.

55. Nisce LZ, Tome MA, He S, Lee BJ III, Kutcher GJ. Management of coexisting Hodgkin's disease and pregnancy. Am J Clin Oncol. 1986; 9(2):146-151.

56. Kal HB, Struikmans H. Radiotherapy during pregnancy: fact and fiction. Lancet Oncol. 2005;6(5):328-333.

57. Woo SY, Fuller LM, Cundiff JH, et al. Radiotherapy during pregnancy for clinical stages IA-IIA Hodgkin's disease. Int J Radiat Oncol Biol Phys. 1992;23(2):407-412.

58. Li FP, Gimbrere K, Gelber RD, et al. Outcome of pregnancy in survivors of Wilms' tumor. JAMA. 1987;257(2):216-219.

59. Chiarelli AM, Marrett LD, Darlington GA. Pregnancy outcomes in females after treatment for childhood cancer. Epidemiology. 2000; 11(2):161-166.

60. Boice JD Jr, Tawn EJ, Winther JF, et al. Genetic effects of radiotherapy for childhood cancer. Health Phys. 2003;85(1):65-80.

61. Winther JF, Boice Jr JD, Frederiksen K, et al. Radiotherapy for childhood cancer and risk for congenital malformations in offspring: a populationbased cohort study. Clin Genet. 2009;75:50-56.

62. Schull WJ, Neel JV. Radiation and the sex ratio in man. Science. 1958; 128(3320):343-348.

63. Hawkins MM, Smith RA. Pregnancy outcomes in childhood cancer survivors: probable effects of abdominal irradiation. Int J Cancer. 1989; 43(3):399-402.

64. Winther JF, Boice Jr JD, Svendsen AL, et al. Spontaneous abortion in a Danish population-based cohort of childhood cancer survivors. J Clin Oncol. 2008;26:4340-4346.

65. Meirow D, Nugent D. The effects of radiotherapy and chemotherapy on female reproduction. Hum Reprod Update. 2001;7(6):535-543.

66. Schmidt KL, Andersen CY, Loft A, Byskov AG, Ernst E, Andersen AN. Follow-up of ovarian function post-chemotherapy following ovarian cryopreservation and transplantation. Hum Reprod. 2005;20(12):3539-3546.

67. Doll DC, Ringenberg QS, Yarbro JW. Antineoplastic agents and pregnancy. Semin Oncol. 1989;16(5):337-346.

68. Aviles A, Neri N. Hematological malignancies and pregnancy: a final report of 84 children who received chemotherapy in utero. Clin Lymphoma. 2001;2(3):173-177.

69. Bath LE, Wallace WH, Critchley HO. Late effects of the treatment of childhood cancer on the female reproductive system and the potential for fertility preservation. BJOG. 2002;109(2):107-114.

70. Lo PA, Ruvolo G, Gancitano RA, Cittadini E. Ovarian function following radiation and chemotherapy for cancer. Eur J Obstet Gynecol Reprod Biol. 2004;113(Suppl 1):S33-S40.

71. Tewari K, Bonebrake RG, Asrat T, Shanberg AM. Ambiguous genitalia in infant exposed to tamoxifen in utero. Lancet. 1997; 350(9072): 183 .

\section{Dovepress}

reviews, risk $\&$ safety of medical interventions, epidemiology $\&$ biostatical methods, evaluation of guidelines, translational medicine, health policies \& economic evaluations. The manuscript management system is completely online and includes a very quick and fair peer-review system, which is all easy to use. 